\title{
Media representations of British Muslims and hybridised threats to identity
}

\author{
Rusi Jaspal and Marco Cinnirella \\ Department of Psychology, Royal Holloway, University of London, \\ Egham Hill, Egham, Surrey TW20-0EX, United Kingdom
}

\begin{abstract}
Muslims have never before occupied such a central position in the British media, given their general absence from more 'normalised' representational positions such as in popular soaps, literature and reality television. Recent studies reveal the primarily negative 'hypervisibility' of Muslims across the media, which has encouraged negative social representations. Drawing upon relevant concepts from integrated threat theory and identity process theory, this paper argues that British Muslims are increasingly constructed in terms of a hybridised threat to the ethno-national ingroup, consisting of both symbolic and realistic aspects. This account offers a socio-psychological perspective by exploring the potential socio-cognitive and behavioural repercussions of exposure to representations of British Muslims as a hybridised threat. The focus upon identity processes among the non-Muslim British majority elucidates the identity implications of Islamophobic representations in the Press and some of the potential causes of Islamophobic prejudice. It is argued that the principles of continuity, distinctiveness and self-esteem are particularly susceptible to change as a result of such negative media representations. The transition from media representation to dominant social representation is discussed, in addition to the potential implications for intergroup relations.
\end{abstract}

Keywords: Muslims; media representations; threat; identity; identity process theory; integrated threat theory; social psychology

Correspondence: Rusi Jaspal, Department of Psychology, Royal Holloway, University of London, Egham Hill, Egham, Surrey TW20-0EX, United Kingdom. Tel: +44(0)1784 276323. Fax: 01784434347 E-mail: rusi.jaspal@gmail.com

Acknowledgements: This research was supported by the Thomas Holloway research grant (from Royal Holloway, University of London) awarded to the first author. 


\section{Media representations of British Muslims and hybridised threats to identity}

Muslims have never before occupied such a central position in the British media, given their general absence from more 'normalised' representational positions such as in popular soaps, literature and reality television. Recent studies reveal the primarily negative 'hypervisibility' of Muslims across the media, which has encouraged negative social representations. Drawing upon relevant concepts from integrated threat theory and identity process theory, this paper argues that British Muslims are increasingly constructed in terms of a hybridised threat to the ethno-national ingroup, consisting of both symbolic and realistic aspects. This account offers a socio-psychological perspective by exploring the potential socio-cognitive and behavioural repercussions of exposure to representations of British Muslims as a hybridised threat. The focus upon identity processes among the non-Muslim British majority elucidates the identity implications of Islamophobic representations in the Press and some of the potential causes of Islamophobic prejudice. It is argued that the principles of continuity, distinctiveness and self-esteem are particularly susceptible to change as a result of such negative media representations. The transition from media representation to dominant social representation is discussed, in addition to the potential implications for intergroup relations.

Prior to September $11^{\text {th }} 2001$ there was but scant empirical research on newspaper representations of Muslims with the vast majority of work employing non-systematic anecdotal evidence in order to illustrate general trends in media coverage (Richardson, 2004). It was of course after this date that newspapers began to dedicate an unprecedented amount of space, time and attention to British Muslims, their differences from the ingroup and the threats they allegedly pose to the ingroup. Muslims have never before occupied such a central position in the British media, given their general absence from more 'normalised' representational positions such as in popular soaps, literature and reality television. This perhaps explains the primarily negative 'hypervisibility' of Muslims across the media, which has encouraged social representations of negativity and threat (Archer, 2009). This unprecedented media attention has indeed been matched by an increasing academic interest in representations of Muslims in the Press primarily from scholars working within journalism studies (Poole, 2002, 2006; Richardson, 2004). The present paper provides fresh insights in this field by presenting a socio-psychological approach to media representations of British Muslims. More specifically, the paper argues that exposure to dominant media representations, which are identified in the literature, can have important implications for identity principles among the primary readership of British newspapers, that is, the White British majority. It will be argued that the perception of identity threat in the dominant majority, as a result of exposure to such media representations, will induce coping strategies, such as the manifestation of Islamophobic attitudes and behaviour. Integrated threat theory is

employed to conceptualise the nature of threats allegedly posed by British Muslims and the potential repercussions for identity principles in the ethno-national ingroup are extrapolated from key predictions associated with identity process theory. 


\section{Theories from social psychology}

\section{Identity process theory}

The central focus of the present paper concerns the potential impact of media representations of Muslims for identity processes among the non-Muslim dominant majority. The present section describes identity process theory (IPT; Breakwell, 1986, 1992, 2001; Vignoles et al., 2006; Jaspal \& Cinnirella, in press). IPT proposes that the structure of identity should be conceptualised in terms of its content and value/ affect dimensions and that this structure is regulated by two universal processes, namely the assimilation-accommodation process and the evaluation process. The assimilation-accommodation process refers to the absorption of new information in the identity structure and of the adjustment which takes places in order for it to become part of the structure. The evaluation process confers meaning and value on the contents of identity.

Breakwell (1986, 1992) has identified four identity principles which are said to guide these universal processes, namely continuity across time and situation, uniqueness or distinctiveness from others, feeling confident and in control of one's life, and feelings of personal worth or social value. IPT refers to these, respectively, as continuity, distinctiveness, self-efficacy and self-esteem. Extending IPT, Vignoles and colleagues (Vignoles, Chryssochoou \& Breakwell, 2002; Vignoles et al., 2006) have proposed two additional identity 'motives', namely belonging, which refers to the need to maintain feelings of closeness to and acceptance by other people, and meaning, which refers to the need to find significance and purpose in one's life. More recently, Jaspal and Cinnirella (in press) have introduced the psychological coherence principle, which refers to the individual's subjective perception of compatibility between their (interconnected) identities (see also Jaspal \& Coyle, 2009a). IPT suggests that when any of these identity principles are obstructed by changes in the social context, for instance, identity is threatened and the individual will engage in coping strategies to alleviate the threat and to minimise the negative repercussions of experiencing identity threat. Accordingly, a coping strategy is defined as 'any activity, in thought or deed, which has as its goal the removal or modification of a threat to identity' (Breakwell, 1986, p. 78).

There are a number of factors which elucidate the heuristic value in IPT. Firstly, the theory explains the psychological factors underlying the experience of identity threat and the possible ways in which individuals might react to their threatened identities. To that end, it conceptualises the cognitive and behavioural patterns manifested by participants in terms of strategies for coping with, or averting in the first place, identity threat. Secondly, its integrative nature enables the researcher to consider the relationships between the identity principles, which remains an important, and largely under-explored, theoretical question in the IPT literature (Breakwell, 1986; Jaspal \& Cinnirella, in press; see Vignoles et al., 2000 for an exception). Exploring these relationships may provide further insight into the socio-psychological reasons that British Muslims may be construed by non-Muslim readers as particularly threatening. An important theoretical point is that, although most IPT studies have examined individual identity, the motivational principles associated with IPT are not necessarily restricted to the individual 
level of cognition, but may in fact be applied to the group level (Lyons, 1996). Thus, it is possible to talk of group self-esteem, group continuity, group distinctiveness and so on.

IPT has received a great deal of empirical support, both quantitative and qualitative, which suggests that it constitutes a fairly robust theoretical tool to consider the potential social and psychological reactions of individuals who perceive their identities as being threatened. It has been employed to interpret inter alia the construction of gay and lesbian identity (Coyle, 1991; Coyle \& Rafalin, 2000; Markowe, 2002), to explore the identity implications of migration and relocation (Timotijevic \& Breakwell, 2000; Speller, 2000), the management of conflictual identities (Jaspal \& Coyle, 2009a Jaspal \& Cinnirella, in press), the role of language in identity (Jaspal \& Coyle, 2009a, 2009b, 2010), the impact of unemployment upon identity (Breakwell et al., 1984) and the role of the Holocaust in Israeli Jewish identity construction (Jaspal \& Yampolsky, 2010). The sheer thematic, as well as methodological, diversity of these studies which have employed the theory attest to its flexibility and robustness in explaining identity threat and the plethora of coping strategies which may be developed and enacted by individuals with threatened identities. Furthermore, it is a model which seeks to explain the effects of social change upon identity (Breakwell, 1986). These are important factors underlying our decision to advocate the use of IPT in considering the potential social and psychological implications of media representations of British Muslims for the ethno-national ingroup. It will be argued that there exists a need for a broad, inclusive theory of identity threat, such as IPT, which identifies multiple identity principles and which provides scope for the exploration of intrapsychic, not just interpersonal and intergroup, processes.

One of the major credentials of IPT lies in its identification, description and elaboration of the various coping strategies in which individuals will engage upon perceiving identity to be threatened. These are fluid and subjective since different forms of identity threat will require the use of distinct coping strategies. Moreover, some strategies are said to be more effective than others in the long-run. Coping strategies differ according to the level of human interdependence; IPT identifies intrapsychic, interpersonal and intergroup coping strategies (Breakwell, 1986). While coping strategies may fit broadly within these three levels of human interdependence, they are likely to differ qualitatively according to the individual and/ or culture in question. Indeed, IPT theorists have identified and described coping strategies not originally accounted for by the theory (e.g. Jaspal \& Cinnirella, in press), and the theory actively encourages this. The conceptualisation of socio-psychological action, which is intended to enhance the identity principles and to ensure the principled operation of identity processes, in terms of coping strategies is beneficial at the theoretical level. This allows researchers to theorise the relationships between a given media representation of British Muslims, which may violate a particular identity principle, and the ensuing cognitive or behavioural response, which seeks to alleviate the threat. This is one of the aims of the present paper.

IPT acknowledges the importance of social representations in shaping how social phenomena will impact the principled operation of identity processes (Breakwell, 1986, 2001). For Breakwell (1986, p. 55), 'social representation is essentially a construction of reality', which 
enable individuals to interpret the social world and to render it meaningful. The two processes of social representations include 'objectification', whereby abstract phenomena (e.g. Islam) are rendered concrete (e.g. the veil), and 'anchoring' which is the means by which unfamiliar phenomena are integrated into existing ways of thinking (Moscovici, 1988). IPT postulates that identity processes will determine how the individual will 'personalise' a representation, that is, the extent to which an individual will accept and internalise the social representation. Conversely, social representations are said to shape the content and value dimensions of identity (Breakwell, 2001). The social representational dimension of IPT is fundamental for understanding media representations and how they subsequently become social and then personal representations.

Having outlined the model of identity processes employed in the present paper, it is necessary to introduce briefly a theoretical model, which accounts for the distinct types of threats which British Muslims may be constructed as posing to the ethno-national ingroup. One such theoretical model is integrated threat theory.

\section{Integrated threat theory}

Given the pervasive tendency for media reports to emphasise the threatening nature of Muslims and, more specifically, their ability to threaten the ethno-national ingroup, it is suggested that integrated threat theory (ITT; Stephan \& Stephan, 2000) offers much heuristic value for conceptualising and understanding the nature of these threats. The theory posits that there are three types of threat, which predict prejudicial attitudes towards outgroups: realistic threats, symbolic threats and intergroup anxiety. Given their relevance in exploring the rhetorical construction of threat in media articles, only realistic and symbolic threats will be discussed in this paper. The present section describes these two categories of threat from ITT in terms of their possible implications for the motivational principles associated with IPT. More specifically, we discuss how intergroup threat may translate into intrapsychic threat.

Realistic threats refer to perceived threats to the economic and political power or position of the ingroup, as well as perceived threats to the physical and economic well-being of the ingroup and its members. For instance, in a meta-analytic review of intergroup threat and outgroup attitudes, it was hypothesised that the negative stereotype that Blacks are violent and aggressive may make White Americans fear for their physical well-being and, thus, construe Blacks in terms of a realistic threat (Riek, Mania \& Gaertner, 2006). Given the rise in Islamophobic social representations associating Muslims with terrorist activity reported in many media analyses, it is possible that British Muslims may be construed by sections of the general population as a realistic threat. The impact of such threats for identity principles is likely to depend upon the nature of the realistic threat itself. For instance, the perception that British Muslims are terrorists who wish to annihilate the non-Muslim British majority may severely compromise the continuity principle of identity, since the implication is that the ingroup risks annihilation, thereby, ceasing to exist as an ethno-national group. On the other hand, the perception that immigrants to Britain pose threats to the economic well-being of the ingroup by 
'taking our jobs' may threaten the self-efficacy principle of identity, given that ingroup members may feel that they lack competence or control over their jobs and lives in general.

Symbolic threats refer to the perceived violation of symbolic self-aspects which are perceived by group members as underlying ingroup identity (e.g. morals, norms, values, standards, beliefs, attitudes, social representation; see Simon, 2004). Moreover, ITT researchers have described symbolic threats as consisting of perceived group differences in worldviews of ingroup and outgroup members' (Corenblum \& Stephan, 2001, p. 253). Clearly, some selfaspects are perceived by group members as endowing their group with a sense of distinctiveness from other groups (Simon, 2004). For example, a value frequently regarded as being associated with Britishness is that of 'freedom of speech', which was widely perceived to be violated by British Muslims who called for the banning of the novel The Satanic Verses during the Rushdie Affair (Modood, 1990). Since this value is construed as differentiating the national ingroup from many national outgroups, the social representation that British Muslims contested this British value perhaps threatened the distinctiveness principle of national identity. In other words, a symbolic threat may be conducive to threats to the distinctiveness principle of identity. Moreover, like realistic threats, symbolic threats might also jeopardise the perceived continuity of the ingroup. For example, the British National Party (BNP), a far-right political party in Britain, frequently depicts British Muslims as seeking 'the destruction of our way of life and everything we hold dear as a people and a nation' (Barnes, 2005, cited in Wood \& Finlay, 2008, p. 715). In this quote, the BNP is alluding to the symbolic threat posed by Muslims given their radically different worldview from that of the ingroup. This is likely to threaten the continuity of ingroup identity given that Muslims are depicted as seeking to bring about, in a malevolent and forceful manner, the destruction of what the ingroup collectively wishes to maintain. In other words, they are depicted as seeking to install discontinuity in the ingroup's lives.

The reconciliation of ITT and IPT adds a further layer of complexity to research on threat perception. The perception of realistic or symbolic threats to the ethno-national ingroup are said to have negative outcomes for intergroup relations (Stephan \& Stephan, 2000), but relevant strands of IPT may elucidate the reasons why individuals are motivated to behave in certain ways in the intergroup setting. Crucially, while ITT conceptualises the nature of threats manifested in the Press, IPT provides insight into the potential repercussions of these threats for identity processes.

Turning to the substantive literature on media representations of Muslims, the following sections consider, through the interpretive lens of ITT and IPT, the ways in which British Muslims are said to be represented in the Press.

\section{'Us' and 'them': processes of group polarisation}

It has been observed that British Muslims are frequently constructed as the antithesis of the ethno-national ingroup. This ingroup-outgroup polarisation is achieved through the representation of negative characteristics as inherent in the Muslim outgroup vis-à-vis the positive characteristics of the ethno-national ingroup. Such group polarisation is frequently 
conceived in terms of the opposition between 'the Muslim World' and 'the West', which echoes the central argument of Edward Said's (1978) well-known book Orientalism. The book argues that dominant social representations construct Islam in an antithetical position to 'the West'. Moore, Mason and Lewis (2006) argue that these are the terms in which Islam and Muslims have become a meaningful homogeneous entity for newspaper readers in the Western world. It is a common rhetorical strategy to establish rigid, impermeable boundaries delineating the ingroup from the outgroup (Bar-On, 2008). Group polarisation in this way is likely to enhance identity in a number of ways. Firstly, the distinctiveness principle benefits from the establishment and maintenance of a sense of differentiation from other groups (Breakwell, 1986; Vignoles et al., 2000). Group polarisation unambiguously presents ethno-national ingroup members with social representations of 'who we are' vis-à-vis 'who we are not', which is said to constitute an important precursor to identity construction (Jaspal \& Cinnirella, 2010). Secondly, the selfesteem principle of (social) identity is likely to be enhanced by ingroup bias and outgroup derogation (Breakwell, 1986; Hogg \& Abrams, 1990), which ensues from evaluative group polarisation as discussed in previous media analyses (van Dijk, 1991; Poole, 2002; Richardson, 2004).

The literature elucidates a number of rhetorical strategies for maintaining group polarisation. For instance, in her discursive analysis of a Spanish broadsheet newspaper, MartinRojo (1995) argues that the rhetorical strategy of textual or discursive exclusion (by 'marking out' Muslims) is articulated on two principal axes. The first axis is 'division'; that is, by delineating the ingroup from the outgroup. An example of this is the widespread use of the noun phrase 'the Muslim world' as if this constituted a homogeneous social entity in opposition to 'us in the West'. This particular axis is likely to benefit the distinctiveness principle since it establishes the sense of intergroup differentiation required in order for group members to acquire a meaningful sense of identity (Codol, 1981; Breakwell, 1986). The second axis is 'rejection', whereby Muslims are segregated, marginalised and discussed in terms of negative social representations. In order to 'reject' Muslims, negative self-aspects will be emphasised, which leads to the social representation that the outgroup (with its values, beliefs and self-aspects) is in direct opposition to the ingroup. Thus, this could be described in terms of a distancing or confrontational schema (Richardson, 2004). Clearly, this axis reflects a strategy of enhancing self-esteem since it encourages a positive conception of oneself and of one's group membership (Gecas, 1982; Breakwell, 1986). The rhetorical rejection of Muslims through the invocation of their negative traits implicitly originates from the social representation that British Muslims are unlike 'us', since 'we' are righteous, moral and tolerant.

These rhetorical strategies of maintaining group polarisation are described in British media studies. For instance, Richardson (2004) concludes that these newspapers engage in the processes of division and rejection in a tripartite procedure. Firstly, a social, psychological or physical space is identified and associated with Muslims; this is rhetorically separated from 'our' space. Secondly, newspapers explain the workings and composition of this space in contrast to 'our' space, which facilitates the process of 'differentiation'. These interrelated stages have 
obvious benefits for intergroup distinctiveness, since they establish rigid boundaries between the ingroup and outgroup and then disseminate social representations regarding those self-aspects which differentiate the two groups (Vignoles et al., 2000). These social representations serve to construct group differences in terms of a tangible, perceptible 'reality'. Finally, newspapers confer upon this space and upon its composition a negative social value, which is termed 'negativisation'. As discussed above, it is this process of outgroup negativisation/ derogation that enables the ethno-national ingroup to derive a sense of self-esteem (Breakwell, 1986).

Processes of negativisation in relation to British Muslims are exemplified by the theme of 'cultural clash', which is observable in media representations of the Muslim presence in Britain. For instance, Poole (2002) notes the prominence of this theme in the British Press during the Sarah Cook Affair, which referred to the case of a 13-year-old British girl who married an 18year-old Turkish waiter while on holiday in Turkey. Poole argues that the social representation of 'cultural clash' between Muslims and the West was reproduced partly through the invocation of a series of dichotomous social representations emphasising group polarisation. The dichotomous representation 'freedom versus constraint' was frequently illustrated by featuring young Sarah Cook wearing the Islamic veil and other Islamic dress. This seemed to contribute to the social representation that the freedom of Sarah Poole, an ethno-national ingroup member, was under threat from (outgroup) Muslim norms, values and traditions. Crucially, Britishness embodied freedom while the Islamic veil symbolised constraint (Richardson, 2004). These social representations may be reinforced through anchoring of the event and, more specifically of Sarah Poole's depiction in Islamic dress, to dominant social representations of the Islamic veil as a symbol of a patriarchal and oppressive Islam, which represses women (Hirschmann, 1997). It is noteworthy that this 'cultural clash' is not depicted in terms of mere intercultural difference but rather as inherent, value-laden identity aspects which allegedly demonstrate the (im-)morality of either group (Poole, 2002). The dichotomy consisting of positive elements attributed to the ingroup and negative elements to the outgroup has obvious benefits for the self-esteem principle.

This leads to an additional dichotomous social representation, namely that of British Muslims' immorality vis-à-vis British morality. Poole (2002) concludes that Muslim-ness is frequently problematised and constructed as a causal factor underlying immoral behaviour. She notes that even 'quality newspapers' such as The Times constructed as Muslim schooling as inferior to British schooling, due to the allegedly inferior morals, values and traditions associated with Muslim identity. Social representations of (im-)morality are likely to be anchored to representations of (ab-)normality, given that the invocation of difference from the ingroup is said to constitute a means of morally denigrating the Other (Rothbart \& Korostelina, 2006). Indeed, 'normality' is defined in line with the norms and values of the ethno-national ingroup, which allows for the 'abnormalisation' of the ethno-religious outgroup, due to their constructed deviance from ingroup norms, values and representations (Verkuyten, 2001). Poole (2002, p. 186) concludes that 'the Press emphasises inherent cultural differences and conflict in order to create symbolic boundaries which function to keep (illusory) categories of people stable and to maintain power relations through the polarization of groups'. Thus, in addition to the 
distinctiveness and self-esteem principles, it is likely that the self-efficacy principle will benefit from the maintenance of power relations which favour the ethno-national ingroup (Breakwell, 1992). The perception of social power in the ingroup's favour is likely to endow ethno-national ingroup members with feelings of competence and control in the intergroup situation. Ingroup members will perceive the social context (with its dominant ideologies and social representations highlighting the ingroup's social power) as facilitating the self-efficacy principle. Indeed, this principle is said to constitute a defining feature of identity (Codol, 1981).

On the one hand, media representations seem to enhance the ethno-national ingroup's identity principles but, on the other hand, media representations of British Muslims may also serve as a threat to the ingroup.

\section{The emerging social representation of hybridised threats from Muslims}

Like other ethnic and religious minorities in Britain, British Muslims have generally been constructed by the British Press in negative terms. However, subsequent to the major intergroup events involving Muslims and the White British majority, media reports tend to focus on a limited set of more specific themes, which emphasise the allegedly threatening nature of Muslims (Poole \& Richardson, 2006). The realistic threat said to be posed by Muslims is frequently conceived in terms of terrorism, which is attested by some of the quantitative findings provided by Moore, Mason and Lewis (2008). In the content analysis of 974 newspaper articles between 2000 and 2008, they identified three major 'news hooks', namely (i) terrorism or the war on terror; (ii) religious and cultural issues; and (iii) Muslim extremism. In terms of ITT, these three news hooks construct different forms of threat posed by the ethno-religious outgroup Muslims, with differing implications for identity principles among the ethno-national ingroup.

In their study, they observed that $36 \%$ of stories about British Muslims concerned terrorism and that this representational tendency became particularly notable after the terrorist attacks in the US in 2001 and in the UK in 2005. According to ITT, in these stories British Muslims are constructed in terms of a realistic threat given that they are said to be involved in terrorist attacks against the ingroup. These terrorist attacks may be perceived as seeking to bring about the destruction of the ethno-national ingroup. Given the significant proportion of stories which associate Muslims with terrorism, it is likely that their respective social representations will converge and that the personal representations subsequently developed by newspaper readers will come to associate Muslims with terrorism (Breakwell, 2001; Lewis, 2001). Thus, it is possible that the experience of perceiving the ingroup, and by extension oneself, as facing realistic threats from British Muslims may potentially threaten the continuity principle of identity (Breakwell, 1986). As discussed above, this is due to the ensuing personal representation that the ethno-national ingroup is at risk of annihilation by the Muslim outgroup.

Crucially, since 2005, the anchoring of British Muslims to themes of terrorist threat does not seem to have declined; in fact, in 2008 alone approximately two thirds of the stories examined focused upon themes of terrorist threat and extremism (Moore et al., 2008). The constructed threat of terrorism comes to constitute a potent realistic threat partly through the 
media's invocation of social representations concerning international events involving Muslims in its discussion of British Muslims. For instance, Richardson (2004) notes the terrorist threat from British Muslims may be anchored to representations of the 'military threat' from Iran. Pivotally, this is frequently represented as a unified Muslim threat rather than as a threat originating from a specific nation. Richardson (2004) observations allude to the prevalence of Islamophobic representations among British readers, which will facilitate the anchoring of representations of British Muslim terror to Iranian military threats. Accordingly, social representations concerning the realistic threat become objectified, that is, they become a tangible, perceptible 'reality' for the ethno-national ingroup through comparison with the Iranian military threat. Indeed Said (1981) identifies the 1979 Iranian Revolution as being the initial 'signifier', in Western social representations, of the resurgence of Islam and that it has come to symbolise relations between the West and the Islamic World. Social representations which conflate perceived realistic threats from British Muslims and those from abroad may become entwined and readily accepted by ethno-national ingroup members in the aftermath of the revelation that most of the July $7^{\text {th }}$ bombers were 'home-grown terrorists', that is, British-born individuals (e.g. Phillips, 2006). This is primarily because the media seemed to generalise concerns regarding the loyalty of British Muslims from these 'home-grown terrorists’ (e.g. Kavanagh, 2009).

This consistent trend in media reporting on British Muslims sheds light upon the formation of social representations regarding this ethno-religious outgroup. The representational trend contributes to the social representation that Muslims are generally associated with terrorist activity. Crucially, it seems to signal the transition of the social representation from being a polemic representation, that is, one generated in the course of social conflict or controversy, to potentially becoming a hegemonic representation, that is, one which is consensually shared, coercive and uniform (Moscovici, 1988). Clearly, this is a concerning prospect for intergroup relations.

In the same study, Moore et al., (2008) found that 22\% of overall studies focused upon religious and cultural differences between the British Muslim minority and the dominant White British majority, such as the wearing of veils, dress codes, forced marriages etc. Indeed, this echoes an observation made by Poole (2002, p. 20) that Muslims are frequently depicted in terms of a threat to British 'mainstream' values, which provokes 'integrative concerns'. Moreover, Poole (2002) observes the pervasiveness of media constructions of inherent cultural differences between Muslims and the dominant non-Muslim majority, which are generally represented as being conducive to interpersonal and intergroup tensions. Similarly, Richardson (2004) has convincingly argued that Muslim cultural difference is increasingly discussed in terms of cultural deviance and, in many cases, even cultural threat. From an ITT perspective, such cultural difference could be categorised as a symbolic threat to the ethno-national ingroup. The cultural differences, which are frequently depicted in the Press, appear to refer to perceived discrepancies in the morals, values, standards, beliefs and attitudes associated with the worldview of either group (Stephan \& Stephan, 2000). Consequently, given that British Muslims are depicted as 
deviating from, and threatening, the worldview of the ethno-national ingroup, they could be viewed as posing a symbolic threat.

Dominant social representations of symbolic threat of this kind are likely to threaten the continuity principle of identity since perceived threats to ingroup self-aspects or to the worldview of the ingroup are likely to jeopardise the perception of 'continuity across time and situation' within identity (Breakwell, 1986, p. 24). The threat ensues from the perceived contravention of the social representation that the worldview of the ethno-national ingroup is the dominant, 'correct' one, which should be consensually shared and adopted by group members. The perception that British Muslims may in fact lay claim to distinct self-aspects constitutes the source of the symbolic threat. This in turn violates the continuity principle, since it queries accepted and internalised social representations which favour the ethno-national ingroup's worldview (Breakwell, 2001). Furthermore, media representations of cultural difference between Muslims and non-Muslims may also compromise the self-esteem principle of identity. Dominant theories of (social) identity generally agree that groups will maintain feelings of selfesteem by regarding their group membership and everything that is associated with it in particularly positive terms vis-à-vis outgroups (Tajfel, 1981; Breakwell, 1986). Accordingly, it can be assumed that group members will perceive self-aspects associated with ingroup identity, as well as their worldview, in positive terms. Thus, given that media representations generally associate Muslims' attempts to preserve aspects of their heritage culture with deviance from and the rejection of ingroup self-aspects (Poole, 2002; Richardson, 2004), this may in turn give rise to the social representation that Muslims devalue or 'inferiorise' self-aspects associated with the White British majority. The perception that ingroup self-aspects are not consensually valued by others may impede 'the motivation to maintain and enhance a positive conception of oneself [and of one's group]' (Gecas, 1982, p. 20). Indeed, there is empirical evidence that threats to the selfesteem principle of identity may result in intergroup discrimination (Fein \& Spencer, 1997).

The third news hook identified in the work of Moore et al. (2008) refers to the constructed ubiquity of extremism among Muslims. It was found that $11 \%$ of stories reproduced the social representation that extremism is ubiquitous among Muslims. Conversely, only $2 \%$ of the 974 newspaper stories analysed 'contained the proposition that Muslims supported dominant moral values' (Moore et al., 2008, p. 3). This news hook is interesting since it features aspects of the two aforementioned news hooks. There are social representations which conflate the notions of religious extremism, fundamentalism and terrorism (Poole, 2002; Herriot, 2008). Given its constructed contribution to terrorism against the ethno-national ingroup, extremism among British Muslims may be perceived as a realistic threat. On the other hand, social representations of Muslim extremism construct Muslims' violation and rejection of the ethno-national ingroup's symbolic beliefs, norms and values as a symbolic threat manifested in an extreme and forceful fashion. Crucially, extremists are depicted as contesting and problematising the ingroup's dominant worldview, which is symbolically threatening.

Reflecting these three news hooks, Poole (2006), in her study of the British print news media in 2003, has found that the main topics associated with Muslims are 'terrorism', 'politics' 
and 'reactions to the war in Iraq'. The media's focus upon these three phenomena seems to encourage the emerging social representation that British Muslims constitute a multifaceted threat to the ethno-national ingroup. This is primarily because 'they', both fundamentalist Muslims and moderate Muslims, are represented as seeking to destroy 'us', both in realistic and symbolic terms (see Wood \& Finlay, 2008). Their constructed opposition to self-aspects associated with the ethno-national ingroup represents an amalgamation of both symbolic and realistic threats. British Muslims' 'questionable' loyalty to the nation and their contested sense of belonging may be construed in terms of a symbolic threat, but their negative repercussions for integration, social cohesion and ultimately the physical well-being of the ethno-national ingroup render this a realistic threat (Moore et al., 2008; see also Werbner, 1994). Consequently, it is argued that British Muslims are represented as posing a 'hybridised' threat to the ethno-national ingroup, since both 'moderate' and 'extremist' Muslims are, to varying degrees, depicted as imperilling the ingroup's continuity. The boundaries between symbolic and realistic threats, which are described by ITT, become blurred in media representations of British Muslims. This elucidates the heuristic value in employing the notion of hybridised threats in relation to such media representations.

The emerging social representation of the hybridised threat from British Muslims may be extrapolated from the empirical findings of Poole (2002, 2006). Her multi-methodological studies of the British Press exemplify the pervasive media representation of British Muslims in terms of both realistic and symbolic threats to the nation. Like Moore et al. (2008), she identifies similar salient news hooks which are observable in the British Press, namely (i) that Muslims constitute a threat to British national security due to their involvement in deviant activities (realistic threat); (ii) that they pose a threat to British values and traditions and thus provoke integrative concerns (hybridised threat); and (iii) that there are inherent cultural differences between Muslims and White Britons which give rise to inevitable tensions in interpersonal relations (hybridised threat). Coterminous with the arguments presented above, it seems that, under close scrutiny, many of the threats constructed in the British Press incorporate features of both realistic and symbolic threats, which may result in the construction of Muslims as a particularly threatening group. This perhaps serves to exaggerate the threats allegedly posed by the ethno-religious outgroup. It has been argued that this is particularly threatening for the continuity principle of identity given that the very essence of the ingroup, such as its future and physical and symbolic well-being, is perceiving as facing threats from the outgroup (Breakwell, 1986). Thus, the exaggeration of these threats has particular repercussions for this identity principle.

Of particular concern is the pervasiveness of these constructed threats, given that the aforementioned news hooks are by no means confined to the British context, but are observable in media reporting in other national contexts. For instance, Richardson (2006) notes that in the Australian Press Muslims are overwhelmingly portrayed as an inherently violent people with terrorist links, who are determined to contravene and to contradict an imagined 'mainstream' Australian culture (see also Manning, 2006). This echoes the notion that Muslims are 
constructed in terms of a hybridised threat. Similarly, the constructed negativity of the Islam as an ideology and Muslims as religious group members has also been identified by media research conducted within the Canadian context (Elmasry, 2002) and in the European Union (Feteke, 2002). This is noteworthy because it demonstrates the ever-increasing, uncritical acceptance and reproduction of negative social representations of Muslims across the global media. Theoretically, it could be stated that the constructed negativity of Muslims is in the midst of an important transition from media representation to hegemonic social representation, that is, they are becoming consensually shared, coercive and uniform (Moscovici, 1988). This is concerning given that previous rhetorical research has demonstrated that hegemonic, pervasively shared social representations often provide individuals with little scope for re-construal and contestation resulting in the uncritical acceptance and reproduction of these representations (Jaspal \& Coyle, 2009a). This essentially means that the reproduction of Islamophobic representations in everyday talk may become a commonplace or even an aspect of common-sense (Moscovici, 1981). Only the systematic consideration of social representations can elucidate the extent of the constructed hybridised threat from British Muslims.

\section{Increasing the threat through social representational conflation}

Discursive and rhetorical research studies have elucidated the heuristic value of micro-level analyses of linguistic representation (van Dijk, 1991; Richardson, 2004). Moreover, Fowler (1991, p. 10) has convincingly argued that 'anything that is said or written about the world is articulated from a particular ideological position; language is not a clear window, but a refracting, structuring medium'. Indeed, ideology is a central concern of researchers working within the domain of social representations (see Deaux \& Philogène, 2001). In light of the assumption that specific categories will evoke distinct sets of social representations, the present section focuses upon the use of categories in media reporting on British Muslims and the possible implications for identity threat.

There appears to have been a terminological shift in media representations of British Muslims. For instance, Poole (2002) notes that, while media reporting prior to September $11^{\text {th }}$ 2001 tended to employ the term 'fundamentalism' in relation to Muslims, more recent reporting has made considerably greater use of the term 'terrorism'. Thus, reporting has converged dramatically around the related notions of terrorism and counter-terrorist measures/ legislation (Poole, 2002). The potential implications of this shift in terminology become clearer when one considers the contention that fundamentalism is not necessarily associated with violence although social representations of fundamentalism may suggest otherwise (Herriot, 2008). Accordingly, fundamentalism associated with the ethno-religious group could be understood to represent a symbolic threat to ethno-national ingroup members, due to the perception of distinct fundamentalist worldview and their perceived attempts to impose upon the ethno-national ingroup this alien worldview (Stephan \& Stephan, 2000). The notion of terrorism is unambiguously threatening at the realistic level, given that it seeks to harm, physically and psychologically, the well-being of the ethno-national ingroup and its members. However, given 
that two of the most important, pervasive news hooks in British media reporting on British Muslims are terrorism and fundamentalism in this community (Moore et al., 2008), the rhetorical convergence of media representations of fundamentalism and of terrorism is likely to lead to social representational conflation. In other words, their frequent association perhaps comes to indicate their shared characteristics, interchangeability and ultimately their synonymity. This has implications for the type of threat they then come to represent for ethno-national ingroup members; British Muslims will be perceived in terms of a symbolic threat, given their fundamentalist views, but also in terms of a realistic threat, given their terrorist ambitions. Accordingly, such terminological conflation contributes to the emerging social representation of hybridised threats from British Muslims, as discussed in the previous section.

The frequent media association of Muslims and fundamentalism/ terrorism ${ }^{1}$ have certainly had repercussions for general social representations of Muslims, who have come to be perceived by many members of the ethno-national ingroup as having terrorist links or as sympathising with the cause of terrorism (Saeed, 2007). As Poole (2002) notes, by defining activities and individuals as 'terrorist', one promotes draconian solutions such as greater on-thespot searches and the detention of individuals without trials. Thus, the invocation of the category 'terrorist' automatically activates a specific set of social representations, that is, of how the individual should be treated, the rights they should be given and how they are to be positioned in relation to the category British. Furthermore, at a more general level, Cottle (2000, p. 429) argues that groups which are labelled as deviant (and, indeed, terrorism may be viewed as an extreme form of deviance) may be 'dehumanised and demonised leading to both depoliticisation and delegitimation of their claims for wider social acceptance'. In terms of IPT, it is likely that the enhancement of the self-efficacy principle will be at the psychological forefront in such situations, given that, faced with hybridised threats from an outgroup, the ingroup must maintain and enhance feelings of 'competence and control' (Breakwell, 1993, p. 205). Given that selfefficacy constitutes a fundamental human motivation (Deci \& Ryan, 2000), it is likely that individuals will strive to maintain and enhance the principle by 'taking control' in contexts of perceived threat, possibly through the 'depolicisation and delegitimation' of British Muslims (Cottle, 2000, p. 429). In short, such Islamophobic practices may have an underlying cause, namely to enhance the self-efficacy principle of identity in potentially threatening situations.

The media studies discussed in the present paper indicate that the ethno-religious category Muslim is in the process of acquiring negative social representations, which is attributed largely to the nature of media representations of Muslims. More specifically, these articles tend to anchor Muslims to negative phenomena, such as terrorism, cultural clash, immorality etc. Social psychological theories such as that of social representations may elucidate some of the more subtle processes whereby the category Muslim comes to acquire negative social representations. The literature suggests that British Muslims may come to be

\footnotetext{
${ }^{1}$ Note that the notions of fundamentalism and terrorism are presented in terms of an interrelated phenomenon as it is argued that the Press represents them in this way. Moreover, social representations of the two are increasingly entwined.
} 
regarded as a threatening group due to their frequent association and/or comparison with other stigmatised social groups. For instance, it has been argued that the negatively represented issues of asylum seekers and refugees have been conflated with the issue of (Islamic) terrorism (Saeed, 2007). Consequently, the negative social representations associated with either group may become entwined with one another; that is, the perceived characteristics of either group perhaps merge into a threatening whole. Given that asylum seekers, for instance, are seen as posing realistic and symbolic threats to the nation (Greer \& Jewkes, 2005; Pearce \& Stockdale, 2009) and terrorists primarily realistic threats, such conflation is likely to contribute to social representations of hybridised threats from British Muslims. The emergence of this social representation is reflected in the observation that 'Muslim' has come to constitute a useful construct with which to identify and categorise visible minorities who are the subject of public anxiety (Saeed, 2007).

\section{Islamophobic representations: identity-enhancing strategies?}

In addition to the dominant media representations of Islam and Muslims as posing hybridised threats to the nation and to the ethno-national ingroup, due to their constructed involvement in terrorist activity, there is a tendency in the Press to construct Islam as a socially oppressive force. Indeed, this tendency echoes Poole's (2002, 2006) observation that the Press constructs inherent cultural differences between Muslims and non-Muslims which contribute to inevitable tensions in interpersonal relations. For instance, Richard (2004, p. 230) concludes in his studies of the British broadsheet Press that when Muslims engage in negative social activities (e.g. activities perceived as threatening, violent, sexist, intolerant or repressive) this gives rise to 'a reservoir of ideas, or core images about Muslims' in general. This illustrates processes of social representation formation (Moscovici, 1988). The point is that these activities can be rhetorically useful in that they provide 'evidence' for the inherent negativity of Islam; that is, the activities confirm and justify negative social representations of Islam (see Ivie, 1980). Saeed and Drainville (2006) argue that, since Muslims are systematically 'otherised' and constructed in terms of an inferior and even barbaric (homogeneous) people, the social representation that terrorism stems from Muslims is easily accepted by individuals. This social representation is of course further compounded by the frequent anchoring of Muslims to representations of fundamentalism and terrorism (Moore et al., 2008). In terms of IPT, it seems that the strategic selection of a limited repertoire of social representations to depict British Muslims may enhance the meaning principle of identity, since this enables individuals to make sense of the surrounding social world, the negativity in this social world and fundamentally to attribute negative phenomena to an outgroup. Moreover, the self-esteem principle may be enhanced by deflecting any shortcoming potentially associated with the ethno-national ingroup from ingroup identity, which enables group members to continue to perceive a positive conception of themselves (Breakwell, 1986).

Conversely, Richardson (2004, p. 131) notes that 'in less negative reporting contexts, the 'Muslim-ness' of Muslim social action is omitted - the reported activities of Muslims are not 
recognised as 'things which Muslims do/ are' and hence they are not picked up on or contextualised in relation to ethno-religious difference. It appears that in newspaper reporting the ethno-religious identity of Muslim wrongdoers is emphasised in negative contexts so that negativity may come to be perceived as a self-aspect inherent in the Muslim community, while in more positive contexts Muslims tend to be 'individualised' with the possible psychological result that newspaper readers perceive no link between the righteous individual and the ethno-religious identity category Muslim. The continuity of a social representation associated with the ethnonational ingroup is protected by eschewing any re-construal or contestation of the representation, which is likely to have positive outcomes for the continuity principle of identity (Breakwell, 1986). Moreover, the consistent construal of British Muslims as posing hybridised threats to the ethno-national ingroup would not be compatible with sporadic constructions of British Muslims in positive terms, which could potentially violate the psychological coherence principle of identity (Jaspal \& Cinnirella, in press). Consequently, it seems that media reporting on British Muslims may serve to enhance the identity principles of the ethno-national ingroup.

The social and psychological 'resources' available for protecting the identity principles will be employed by individuals. For instance, although many media analysts and scholars working in journalism studies attribute the negative social representations of Muslims to the recent terrorist activities, there are other catalysts for the demonisation of Muslims in the Press which precede $9 / 11$ and the July $7^{\text {th }}$ bombings in London. Ahmed (1992) attributes this to media representations of the Rushdie Affair in the late 1980s which portrayed Muslims as opposing 'British values' such as tolerance, democracy and freedom of speech, that is, they were depicted in terms of a symbolic threat. Together with media representations of Muslim support for Saddam Hussein in the first Gulf War, the represented reactions of British Muslims to the Rushdie Affair perhaps contributed to emerging social representations of Muslim 'social separatism' and of the questionable loyalty of 'Muslims within' (see Werbner, 1994, 2000). Social memory processes may be employed in order to piece together the historically threatening aspects of British Muslims, which illustrate and confirm their threatening essence (see Lyons, 1996; Hilton et al., 1996). Here the concept of 'dormant' social representations is useful (Cinnirella, 1997). This is because social representations of these events involving Muslims, which were largely latent until 9/11, may become reactivated in the minds of individuals in order to reiterate the over-arching representation of British Muslims' intolerance. Social memory processes and the re-activation of dormant social representations regarding British Muslims are likely to fulfil the aforementioned identity principles most susceptible to change (i.e. meaning, continuity and psychological coherence). The media will draw upon historical social representations from other social and temporal contexts in order to enhance identity principles, which will in turn have positive outcomes for ethno-national ingroup members.

It is argued that Islamophobic representations in the Press may, in some cases, enhance identity principles, although, simultaneously, the notion that the ethno-national ingroup faces hybridised threats is likely to jeopardise other identity principles. The Press' enhancement of identity principles is exemplified by the manifestation of negative representations of culture 
rather than 'race'. It is a consensually shared social representation that overt expressions of racism have become unacceptable in modern, civilised society, primarily due to the breakdown of theories of biological inferiority associated with 'race' (Solomos, 1993; Mason, 2000). However, it has been demonstrated that in order to enhance the principles of meaning and continuity the ethno-religious outgroup is derogated, although this process is performed not on the basis of 'race' but culture. As discussed above, Muslims are represented as being uncivilised, culturally inferior and as having a lifestyle which is incompatible with ingroup norms and values (Richardson, 2004). Here there is no necessary claim of biological inferiority, but rather culture and ethnicity are more readily critiqued by the Press given that they are understood to be inherently social rather than biological in nature (Mason, 2000).

Fine-grained analyses of discourse and rhetoric reveal that Muslim culture is frequently represented as being inherently negative and that members of the ethno-religious group are depicted as possessing inherent and immutable characteristics, which, allegedly, are to be found among all Muslims. Thus, this form of outgroup derogation does indeed bear many similarities to the more 'old-fashioned' racism, which invokes biological aspects of groups (see Nelson, 2002), in that these are viewed in essentialist terms as inherent characteristics of the ethnoreligious outgroup. Turning to the psychological coherence principle of identity, this perhaps facilitates the reconciliation of 'racism', which is 'a discourse and a practice whereby ethnic groups are [inherently] inferiorised' (Anthias, 1995, p. 294), and the dominant social representation that there is no place for racism in modern, civilised society (see Jaspal \& Cinnirella, in press). By reproducing racist social representations in a manner which superficially distances them from consensually shared understandings of what constitutes 'racism', one is able to establish coherence and compatibility between the two aspects of one's identity, namely potentially racist personal representations of a given stimulus and one's desired non-racist self (see Markus \& Nurius, 1986). In essence, the intergroup 'tensions' remain the same but the manner in which intergroup derogation is manifested by the Press benefits the psychological coherence principle and, thus, identity in general.

\section{Conclusion}

Rather than merely describing the representational tendencies of the British Press, the present paper considers these representational tendencies through the theoretical lens of IPT and ITT, which adds further theoretical depth to the area of media representations. This has enabled us to theorise, to some extent, the relationships between media representations, social representations and identity processes. It is argued that the frequency and consistency of media representations will determine their eventual transformation into social representations, since the more these representations are reproduced in the media, the more firmly they become ingrained in the social and psychological context. ITT provides insight into the nature of the threat allegedly posed by British Muslims. These threats may be symbolic, realistic or an amalgamation of the two, in which case it constitutes a hybridised threat. The reconciliation of ITT and IPT has allowed for 
theorisation of the potential repercussions of realistic, symbolic and hybridised threats for the principled operation of identity processes.

In line with findings of Jaspal and Cinnirella (in press), it seems that specific principles may be more or less associated with distinct identities and social contexts. In the present context, negative media representations of British Muslims are said to have a dual function for identity. On the one hand, the negativisation of this ethno-religious group is likely to enhance the distinctiveness and self-esteem principles of identity among the readership, since the ingroup is clearly delineated evaluatively from the outgroup. On the other hand, the consistent representation of British Muslims in terms of a realistic, symbolic and hybridised threat to the ethno-national ingroup may jeopardise the continuity principle of identity given the constructed threats to the group's survival 'as a distinctive and collective entity within the intergroup setting' (Giles, Bourhis \& Taylor, 1977, p. 308). It is acknowledged that other identity principles may be affected as a result of exposure to media representations, although it is the three aforementioned principles which are most susceptible to change.

This paints a bleak picture of media representations of British Muslims. The textual manifestation of Islamophobic prejudice perhaps provides the Press with a suitable 'Other' to derive a sense of self-esteem and distinctiveness, although, simultaneously, it fuels social and psychological manifestations of Islamophobic prejudice among the readership. Moreover, given their probable threats to the continuity principle, such media representations are likely to induce feelings of fear, insecurity and hostility among the readership. In short, Islamophobic representations seem to constitute a means of enhancing identity but the social and psychological manifestation of Islamophobia perhaps constitutes a response to threatened identity. As Breakwell (1986, p. 43) convincingly argues, 'action is the social expression of identity. The content and value dimensions of identity specify appropriate action.' Thus, in order to protect the continuity principle, members of the ethno-national ingroup may indeed endorse draconian measures which could be deemed to be Islamophobic (Poole, 2002).

Clearly, the theoretical observations made in this paper merit empirical attention with additional insights from other theoretical frameworks. Meanwhile, one of the primary practical implications of this paper is that there should be attempts to modify the negative social representations of British Muslims, which are largely derived from media representations of this group. This would entail the exploration of alternative methods of enhancing the ethno-national ingroup's identity. Moreover, Islamophobic prejudice as a strategy for coping with threat should be discouraged. Although the identity principles may benefit from Islamophobic representations, the repercussions for intergroup relations are likely to be negative with obvious threats to social harmony and national unity. In conclusion, the Press has a crucial role to play in the process of eradicating Islamophobia and the ensuing threats to society.

\section{References}

Ahmed, A.S. (1992). Postmodernism and Islam. London: Routledge.

Anthias, F. (1995). Cultural racism or racist culture? Rethinking racist exclusions. Economy and Society, 24(2), 279-301. 
Archer, L. (2009). Race, 'face’ and masculinity: the identities and local geographies of Muslim boys. In P. Hopkins \& R. Gale (eds.), Muslims in Britain: Race, Place and Identities. Edinburgh: Edinburgh University Press.

Bar-On, D. (2008). The Others Within Us: Constructing Jewish-Israeli Identity. Cambridge: Cambridge University Press.

Breakwell, G.M. (1986). Coping with threatened identities. London: Metheun.

Breakwell, G.M. (1992). Processes of self-evaluation: efficacy and estrangement. In G.M. Breakwell (Ed.), Social psychology of identity and the self concept (pp.335-355). London: Academic Press/ Surrey University Press.

Breakwell, G. M. (1993). Social representations and social identity. Papers on Social Representations, 2, 198-217.

Breakwell, G.M. (2001). Social representational constraints upon identity processes. In K. Deaux \& G. Philogene (eds.), Representions of the social: bridging theoretical traditions (pp.271-285). Oxford: Blackwell.

Cinnirella (1997). Ethnic and national stereotypes: a social identity perspective. In C.C. Barfoot (Ed.), Beyond Pug's Tour: National and ethnic stereotyping in theory and literary practice (pp.253-274). Amsterdam: Editions Rodopi.

Codol, J. P. (1981). Une approche cognitive du sentiment d'identité [A cognitive approach to the feeling of identity]. Social Science Information, 20, 111-136.

Corenblum, B. \& Stephan, W.G. (2001). White fears and native apprehensions: an integrated threat theory approach to intergroup attitudes. Canadian Journal of Behavioural Science, 33(4), 251-268.

Cottle, S. (2000). Media research and ethnic minorities: Mapping the field. In S. Cottle (Ed.), Ethnic Minorities and the Media: Changing Cultural Boundaries (pp.XX-XX). Buckingham, UK: Open University Press.

Coyle, A. (1991). The construction of gay identity. Unpublished PhD dissertation, University of Surrey, Guildford, UK.

Coyle, A. \& Rafalin, D. (2000). Jewish gay men's accounts of negotiating cultural, religious and sexual identity: a qualitative study. Journal of Psychology and Human Sexuality, 12, 21-48.

Deaux, K. \& Philogène, G. (eds.) (2001). Representations of the social. Oxford: Blackwell.

Deci, E. L., \& Ryan, R. M. (2000). The "what" and "why" of goal pursuits: human needs and the self-determination of behavior. Psychological Inquiry, 11, 227-268.

Elmasry, M. (2002). The Future of Muslims in Canada. Conference Paper October 20 2002. Ottawa, Canada.

Fein, S., \& Spencer, S. J. (1997). Prejudice as self-image maintenance: affirming the self through derogating others. Journal of Personality and Social Psychology, 73, 31-44.

Fekete, L. (2002). Racism, the Hidden Cost of September 11. London: Institute of Race Relations.

Fowler, R. (1991) Language in the News: Discourse and Ideology in the Press. London: Routledge.

Gecas, V. (1982). The self-concept. Annual Review of Sociology, 8, 1-33.

Giles, H., Bourhis, R.Y. \& Taylor, D.M. (1977). Toward a theory of language in ethnic group relations. In H. Giles (Ed.), Language, Ethnicity and Intergroup Relations (pp. 307-348). London: Academic Press. 
Greer, C. \& Jewkes, Y. (2005). Extremes of Otherness: media images of social exclusion. Social Justice, 32(1), 20-31.

Herriot, P. (2008). Religious Fundamentalism and Social Identity. London: Routledge.

Hilton, D.J., Erb, H., Dermot, M. \& Molian, D.J. (1996). Social representations of history and attitudes to European reunification in Britain, France and Germany. In G.M. Breakwell \& E. Lyons (eds.), Changing European identities: social psychological analyses of social change (pp.275-296). Oxford: Butterworth-Heinemann.

Hirschmann, N.J. (1997). Eastern Veiling, Western Freedom? The Review of Politics, 59(3), 46188.

Hogg, M. A., \& Abrams, D. (1990). Social motivation, self-esteem and social identity. In D. Abrans \& M. A. Hogg (Eds.), Social Identity Theory: Constructive and Critical Advances (pp.28-47). New York: Springer-Verlag.

Ivie, R.L. (1980). Images of Savagery in American Justifications for War. Communication Monographs, 47, 279-294.

Jaspal, R. \& Cinnirella, M. (2010). Ethnic identity construction among UK South Asians: insights from identity process theory. Manuscript submitted for publication.

Jaspal, R. \& Cinnirella, M. (in press). Coping with potentially incompatible identities: accounts of religious, ethnic and sexual identities from British Pakistani men who identify as Muslim and gay. British Journal of Social Psychology.

Jaspal, R. \& Coyle, A. (2009a). Language and perceptions of identity threat. Psychology and Society, 2(2), 150-167.

Jaspal, R. \& Coyle, A. (2009b). “My language, my people”: Language and ethnic identity among British-born South Asians. Manuscript submitted for publication.

Jaspal, R \& Coyle, A. (2010). “Arabic is the language of the Muslims - that's how it was supposed to be": Exploring language and religious identity through reflective accounts from young British-born Asians. Mental Health, Religion and Culture, 13(1), 17-36.

Jaspal, R. \& Yampolsky, M. (2010). Social representations of the Holocaust and Israeli Jewish identity construction. Manuscript submitted for publication.

Kavanagh, T. (2009). Will Muslims denounce the atrocities too? The Sun, $16^{\text {th }}$ March 2009.

Lewis, J. (2001). Constructing Public Opinion. New York: Columbia University Press.

Lyons, E. (1996). Coping with social change: processes of social memory in the reconstruction of identities. In G.M. Breakwell \& E. Lyons (eds.), Changing European identities: social psychological analyses of social change (pp.31-40). Oxford: Butterworth-Heinemann.

Manning, P. (2006). Australians imagining Islam. In E, Poole \& J.E Richardson (eds.), Muslims and the News Media (pp.128-41). London: I.B. Tauris.

Markowe, L.A. (2002). Coming out as a lesbian. In A. Coyle \& C. Kitzinger (Eds.), Lesbian and Gay Psychology: New Perspectives (pp.63-80). Oxford: BPS Blackwell.

Markus, H. \& Nurius, P. (1986). Possible selves. American Psychologist, 41(9), 954-969.

Martin-Rojo, L. (1995). Division and rejection: from the personification of the Gulf Conflict to the demonization of Saddam Hussein. Discourse and Society, 6(1), 29-80.

Mason, D. (2000). Race and Ethnicity in Modern Britain. Oxford: Oxford University Press.

Modood, T. (1990). British Asian Muslims and the Rushdie Affair. The Political Quarterly, 61(2), 143-160.

Moore, K., Mason, P. \& Lewis, J. (2008). Images of Islam in the UK: The Representation of British Muslims in the National Print News Media 2000-2008. Cardiff: Cardiff School of Journalism, Media and Cultural Studies. 
Moscovici, S. (1981). On social representations. In J.P. Forgas (Ed.), Social Cognition: Perspectives on everyday understanding (pp.181-209). London: Academic Press.

Moscovici, S. (1988). Notes towards a description of social representations. European Journal of Social Psychology, 18(3), 211-250.

Nelson, T. (2002). The psychology of prejudice. Needham Heights, MA: Allyn \& Bacon.

Pearce, J.M. \& Stockdale, J.E. (2009). UK responses to the asylum issue: a comparison of lay and expert views. Journal of Community \& Applied Social Psychology, 19, 142-155.

Phillips, M. (2006). Londonistan. London: Gibson Square.

Poole, E. (2002). Reporting Islam: Media Representations of British Muslims. London: I.B. Tauris.

Poole, E. (2006). The effects of September 11 and the war in Iraq on British newspaper coverage. In E. Poole \& J.E. Richardson (eds.), Muslims in the News Media (pp.89-102). London: I.B Tauris.

Richardson, J.E. (2004). (Mis)representing Islam: The racism and rhetoric of British broadsheet newspapers. Amsterdam: John Benjamins.

Riek, B.M., Mania, E.W. \& Gaertner, S.L. (2006). Intergroup threat and outgroup attitudes: a meta-analytic review. Personality and Social Psychology Review, 10(4), 336-353.

Rothbart, D. \& Korostelina, K.V. (2006). Moral denigration of the Other. In D. Rothbart \& K.V. Korostelina (eds.), Identity, morality and threat (pp.29-58). Lanham, MD: Lexington.

Saeed, A. (2007). Media, racism and Islamophobia: the representation of Islam and Muslims in the media. Sociology Compass, 1(2), 443-462.

Saeed, A. \& Drainville, E. (2006). Beyond Orientalism: why Palestine is still the issue. Paper presented at the AMPE/MECSA joint conference, Leeds Metropolitan University, 13-15 January 2006.

Said, E.W. (1978). Orientalism. London: Penguin

Said, E.W. (1981). Covering Islam: How the Media and the Experts Determine How We See the Rest of the World. New York City: Pantheon Books.

Simon, B. (2004). Identity in Modern Society: A Social Psychological Perspective. Oxford: Blackwell Publishing Ltd.

Solomos, J. (1993). Race and racism in Britain. Basingstoke: Macmillan Press.

Speller, G.M. (2000). A community in transition: a longitudinal study of place attachment and identity processes in the context of an enforced relocation. Unpublished $\mathrm{PhD}$ dissertation, University of Surrey, Guildford, UK.

Stephan, W.G. \& Stephan, C.W. (2000). An integrated threat theory of prejudice. In S. Oskamp (Ed.), Reducing prejudice and discrimination (pp. 23-46). Mahwah, NJ: Erlbaum.

Tajfel, H. (1981). Human groups and social categories: studies in social psychology. Cambridge: Cambridge University Press.

Timotijevic, L. \& Breakwell, G.M. (2000). Migration and threat to identity. Journal of Community \& Applied Social Psychology, 10(5), 355-372.

Van Dijk, T.A. (1991) Racism and the Press. London: Routledge.

Verkuyten, M. (2001). 'Abnormalization' of ethnic minorities in conversation. British Journal of Social Psychology, 40(2), 257-278.

Vignoles, V.L., Chryssochoou, X. \& Breakwell, G.M. (2000). The distinctiveness principle: identity, meaning, and the bounds of cultural relativity. Personality and Social Psychology Review, 4(4), 337-354. 
Vignoles, V.L., Chryssochoou, X. \& Breakwell, G.M. (2002). Evaluating models of identity motivation: self-esteem is not the whole story. Self \& Identity, 1, 201-218.

Vignoles, V. L., Regalia, C., Manzi, C., Golledge, J., \& Scabini, E. (2006). Beyond self-esteem: influence of multiple motives on identity construction. Journal of Personality and Social Psychology, 90, 308-333.

Werbner, P. (1994). Diaspora and millennium: British Pakistani global-local fabulations of the Gulf War. In A. Ahmed \& H. Donnan (eds.), Islam, Globalization and Postmodernity (pp.209-232). London: Routledge.

Werbner, P. (2000). Divided loyalties, empowered citizenship? Muslims in Britain. Citizenship Studies, 4(3), 307-24.

Wood, C. \& Finlay, W.M.L. (2008). British National Party representations of Muslims in the month after the London bombings: homogeneity, threat, and the conspiracy tradition. British Journal of Social Psychology, 47, 707-726. 